\title{
Subsurface fluid pressure and rock deformation monitoring using seismic velocity observations
}

\section{Journal Article}

\section{Author(s):}

Doetsch, Joseph (D); Gischig, Valentin; Villiger, Linus; Krietsch, Hannes; Nejati, Morteza; Amann, Florian; Jalali, Reza (iD; Madonna, Claudio; Maurer, Hansruedi; Wiemer, Stefan; Driesner, Thomas; Giardini, Domenico

Publication date:

2018-10-16

\section{Permanent link:}

https://doi.org/10.3929/ethz-b-000291857

Rights / license:

In Copyright - Non-Commercial Use Permitted

\section{Originally published in:}

Geophysical Research Letters 45(19), https://doi.org/10.1029/2018gl079009

\section{Funding acknowledgement:}

169178 - A decameter-scale reservoir stimulation experiment - the full hydro-mechanical response of a fault zone to high-pressure water injection (SNF) 


\section{Geophysical Research Letters}

\section{RESEARCH LETTER}

10.1029/2018GL079009

Key Points:

- Seismic velocities measured in 20-m-scale in situ experiment respond directly to high-pressure fluid injections

- In situ measurements of fluid pressure allow validation of seismic velocity measurements as proxy for field-scale pressure monitoring

- Three-dimensional time-lapse seismic velocity tomography allows monitoring of fluid pressure propagation through its relationship to effective stress

Supporting Information:

- Supporting Information S1

Correspondence to:

J. Doetsch,

joseph.doetsch@alumni.ethz.ch

\section{Citation:}

Doetsch, J., Gischig, V. S., Villiger, L., Krietsch, H., Nejati, M., Amann, F., et al. (2018). Subsurface fluid pressure and rock deformation monitoring using seismic velocity observations. Geophysical Research Letters, 45. https:// doi.org/10.1029/2018GL079009

Received 31 MAY 2018 Accepted 20 SEP 2018 Accepted article online 24 SEP 2018

\section{Subsurface Fluid Pressure and Rock Deformation Monitoring Using Seismic Velocity Observations}

\author{
Joseph Doetsch ${ }^{1}\left(\mathbb{D}\right.$, Valentin S. Gischig $^{1,2} \mathbb{D}^{\mathrm{D}}$, Linus Villiger ${ }^{3}$, Hannes Krietsch ${ }^{1} \mathbb{D}$, Morteza Nejati ${ }^{1} \mathbb{D}$, \\ Florian Amann $^{4}$ iD, Mohammadreza Jalali ${ }^{4}$ iD, Claudio Madonna ${ }^{1}$ iD, Hansruedi Maurer' ${ }^{1}$, \\ Stefan Wiemer $^{3}$ iD, Thomas Driesner ${ }^{1}$ iD, and Domenico Giardini ${ }^{1}$ \\ ${ }^{1}$ Department of Earth Sciences, ETH Zurich, Zurich, Switzerland, ${ }^{2}$ CSD Ingenieure AG, Liebefeld, Switzerland, ${ }^{3}$ Swiss \\ Seismological Service, ETH Zurich, Zurich, Switzerland, ${ }^{4}$ Engineering Geology and Hydrogeology, RWTH Aachen, Aachen, \\ Germany
}

Abstract Fluid pressure within the Earth's crust is a key driver for triggering natural and human-induced seismicity. Measuring fluid pressure evolution would be highly beneficial for understanding the underlying driving mechanisms and supporting seismic hazard assessment. Here we show that seismic velocities monitored on the 20-m scale respond directly to changes in fluid pressure. Our data show that volumetric strain resulting from effective stress changes is sensed by seismic velocity, while shear dislocation is not. We are able to calibrate seismic velocity evolution against fluid pressure and strain with in situ measurements during a decameter-scale fluid injection experiment in crystalline rock. Thus, our 4-D seismic tomograms enable tracking of fluid pressure and strain evolution. Our findings demonstrate a strong potential toward monitoring transient fluid pressure variations and stress changes for well-instrumented field sites and could be extended to monitoring hydraulic stimulations in deep reservoirs.

Plain Language Summary The pressure of fluids in the subsurface is generally a function of depth as well as the regional geological history. Changes to the subsurface fluid pressure-be it natural or human induced-disturb the stress field and are known to drive volcanic eruptions, as well as to trigger earthquakes. For example, pressure increase by fluid injection for hydraulic stimulation and wastewater disposal has been linked to earthquake activity. Unfortunately, pressure measurements need direct access through boreholes, so that pressure data are only available for few locations. A method for estimating the spatial distribution of fluid pressure remotely would thus be highly beneficial. From measurements in a 20-m-scale experiment in granite, we find that fluid pressure propagation can be predicted from observed seismic velocity variations, based on a strong correlation between observed changes in seismic velocities and fluid pressure measured within the rock. As seismic velocities can be readily measured on the reservoir scale, our results demonstrate a strong potential of seismic velocity monitoring for remotely estimating fluid pressure changes in deep reservoirs, along faults, or in volcanic systems. The estimated pressure and stress changes could be an important input to real-time risk analysis of fault reactivation and volcanic eruptions.

\section{Introduction}

Fluid pressure migration induces effective stress changes in the Earth's crust that can trigger earthquakes (Husen et al., 2007; Miller et al., 2004; Pezzo et al., 2018). Subsurface pressure evolution therefore is a key observable for understanding and predicting natural subsurface processes and also for obtaining a better grasp on hazardous man-made-induced earthquakes. These have recently been brought to the spotlight due to dramatically increasing levels of seismicity in regions with activities such as hydraulic fracturing to extract shale gas or oil, wastewater injections (Ellsworth, 2013), or hydraulic stimulation to exploit underground geothermal resources (Evans et al., 2005; Häring et al., 2008).

Such injection-induced seismicity is not only an undesirable by-product of these underground operations but also inevitably accompanies the intended rock permeability enhancement (i.e., hydraulic stimulation). The elevated fluid pressure creates new fractures, opens them, or produces slip on existing fractures-all processes that add to improved subsurface fluid mobility essential for extracting gas, oil, or geothermal heat. Thus, clouds of seismicity generated during reservoir creation are often used as means to infer properties of the stimulated rock mass, such as size, shape, and hydraulic diffusivity (Cipolla \& Wallace, 2014; Mayerhofer et al., 2010; Shapiro et al., 1997, 2005).
(C)2018. American Geophysical Union. All Rights Reserved. 
Not all pressure-induced fracture opening or slip radiates seismic energy, but it may also occur silently or aseismically. Such aseismic processes have been proposed for many reservoir stimulation projects (Calò et al., 2011; Cornet et al., 1997; Evans, 1998) but have only recently been directly observed in decameter-scale scientific fault slip experiments (Duboeuf et al., 2017; Guglielmi et al., 2015). Their existence implies that the stimulated volume may be underestimated if solely based on microseismicity clouds. An alternative proxy is offered by an estimate of the entire pressurized volume. It has been suggested (Calò et al., 2011; Hillers et al., 2015; Rivet et al., 2016) that monitoring of seismic velocity changes is a promising tool for measuring pressure propagation and aseismic deformation associated with hydraulic stimulations.

Although seismic velocity variations have been studied in the past in the context of hydromechanical processes (Hillers et al., 2015; Obermann et al., 2015; Rivet et al., 2016), it remains challenging to establish a quantitative link between seismic velocity changes and the pressure field in absence of any direct pressure observations. Such a relationship would be relevant not only for cases of induced seismicity but also for understanding phenomena related to magmatic and hydrothermal volcanic processes, hydrocarbon resources, and pressure migration in tectonically active regions. Pressurized volcanic fluids have been mapped using seismic velocity variations (Brenguier et al., 2014). Also, temporal seismic velocity changes could be correlated with the surface deformation around a volcano observed with radial tilt measurements (Donaldson et al., 2017) indicating that seismic velocity also responds directly or indirectly through pressure changes to crustal deformation. Within the field of hydrocarbon exploration, subsurface pore pressure has been estimated from active seismic data prior to drilling (Sayers et al., 2002). On the larger scale, pore pressure variations have been imaged from active seismic data within subduction zones (Kodaira et al., 2004). Natural pore pressure migration within a tectonically active region has been monitored using repeated earthquake tomography (Chiarabba et al., 2009).

We demonstrate here that seismic velocity variations measured on the field scale are a sensitive and quantitative indicator for even subtle changes in pore pressure and rock deformation. Our data set combines measurements of seismic velocity changes during a decameter-scale fluid injection experiment with independent in situ pressure and strain monitoring that allow unique interpretation and validation of the results.

\section{Fluid Injection Experiment}

The fluid injection experiment (Amann et al., 2018) was carried out at the Grimsel Test Site, located in the Central Swiss Alps. The underground laboratory is hosted within Variscan-aged granitic and granodioritic rocks (Keusen et al., 1989) and consists of a network of tunnels and boreholes that allow direct access to the rock volume. The rock mass within the test volume displays pervasive foliation (strike $\mathrm{N} 50^{\circ} \mathrm{E}$, dip $80^{\circ}$ toward SE) and is intersected by a set of shear zones (S1 and S3) that have formed under ductile (S1) or brittle-ductile (S3) conditions during Alpine orogeny (Keusen et al., 1989). The three ductile S1 shear zones are characterized by an increase in foliation as well as subparallel brittle fractures and have a strike of $\mathrm{N} 52^{\circ} \mathrm{E}$ and a dip of $77^{\circ}$ toward southeast. The two brittle-ductile S3 shear zones within the experimental volume are parallel with a separation of 2-3 $\mathrm{m}$, strike at $\mathrm{N} 93^{\circ} \mathrm{E}$ with a dip of $65^{\circ}$ toward south, and bound a fractured zone (see Krietsch, Doetsch, et al., 2018 for a detailed geological model). Apart from these large-scale structures, the rock mass contains exceptionally few small-scale fractures (0-3 macroscopic fractures per meter; Krietsch, Doetsch, et al., 2018). In the undisturbed rock, the porosity is $<1 \%$ and permeability on the order of $10^{-19} \mathrm{~m}^{2}$ (Wenning et al., 2018). The in situ stress field has been characterized using stress relief (i.e., overcoring) and hydrofracturing techniques. The results show that the maximum principle stress is subhorizontal with a magnitude of 13-14 MPa and an east-west to southeast-northwest strike and that the two other principle stress components are similar in magnitude ranging between 8.6 and 10.2 MPa (Gischig et al., 2018; Krietsch, Gischig, Evans, et al., 2018). The S1 and S3 shear zones both support shear stress so that slip could be activated with injections at 5 and $7 \mathrm{MPa}$, respectively.

During the fluid injection experiment, $1.25 \mathrm{~m}^{3}$ of water was injected into the southern one of the two east-west striking S3 shear zones at pressures up to 7.7 MPa. The injection protocol consisted of four cycles (Figure 1b). Cycles 1, 2, and 4 were pressure controlled to allow systematic evaluation of prestimulation and poststimulation injectivity and jacking pressure. In cycle 3, the main stimulation cycle, the flow rate was controlled and successively increased from $10 \mathrm{~L} / \mathrm{min}$ up to $25 \mathrm{~L} / \mathrm{min}$. Pressure, strain, and seismicity were monitored using sensors at distances of 3.9 to $30 \mathrm{~m}$ from the injection point. Pressure was monitored in 

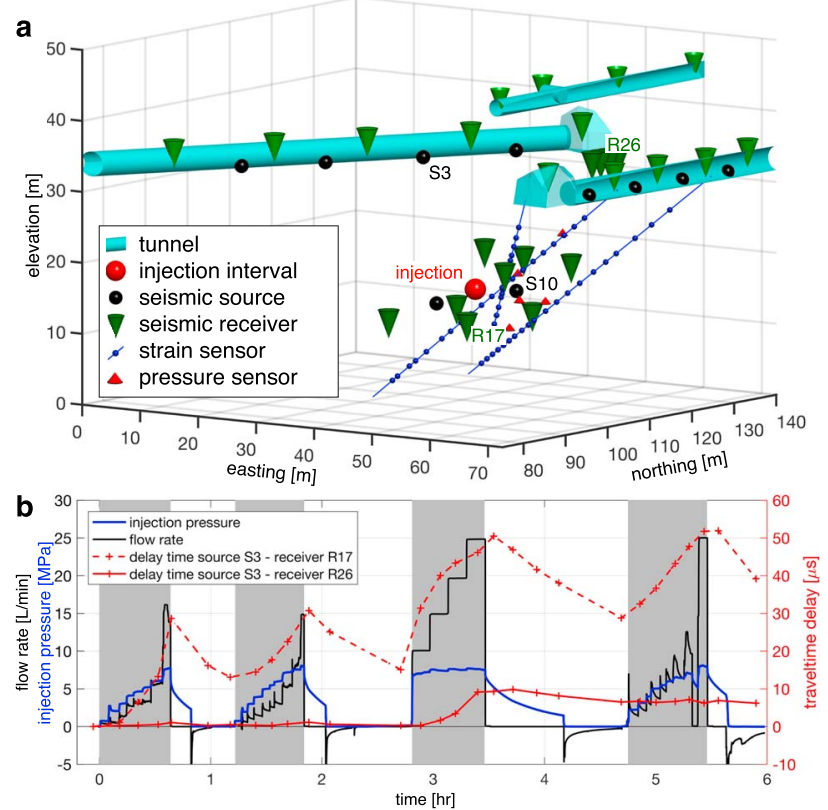

Figure 1. Overview of the geometry and timeline for the stimulation experiment. (a) Overview of the experimental setup of the decameter-scale experiment, including seismic sources and sensors. (b) Time evolution of injection pressure, flow rate, and observed seismic traveltime delays for one source and two receivers during the four injection cycles (gray-shaded areas). eight open borehole sections within the shear zones, in otherwise cemented boreholes. Sixty Fiber-Bragg-Grating sensors with 1-m base length measuring longitudinal strain were installed in three boreholes, oriented approximately parallel and perpendicular to the shear zones (Krietsch, Gischig, Jalali, et al., 2018). Continuous passive seismic monitoring data were recorded using 26 piezo sensors in tunnels and boreholes (Figure 1a), and the processing for detection and localization of induced seismic events followed the workflow of Gischig et al. (2018).

\section{Seismic Monitoring and Measurements of Traveltime Variations}

Active seismic surveys were performed during the fluid injection experiment by repeatedly emitting seismic signals from 10 seismic hammer and piezo sources (Figure 1a). These sources were designed to maximize repeatability of the source wavelet. Inside the tunnels, eight 2-kg hammers (black spheres near tunnels in Figure 1a) were installed on hinges and released from a predefined height, so that they hit a hardened steel pin on the tunnel wall with a well-defined momentum. In addition to the hammer sources in the tunnels, two piezo sources (black spheres below tunnel level in Figure 1a) were installed in monitoring boreholes. As the signal of these piezo sources is weak, signals were stacked 256 times during each survey to increase the signal-to-noise ratio. The hammer and piezo source signals are very repeatable, with waveform correlations $>0.99$ for repeated surveys for most source receiver pairs (Figure $\mathrm{S} 1$ in the supporting information for examples). The seismic signals were recorded using 26 piezo sensors (Figure 1a), with source-receiver distances between 4 and $70 \mathrm{~m}$. Eighteen piezo sensors were installed in the tunnels, and eight receivers were installed in boreholes below the tunnel level and slightly above and below the hydraulic injection point. The hammer signals were retrieved from the continuously recorded seismic monitoring data, sampled at $200 \mathrm{kHz}$. The signals from the borehole sources were recorded separately and sampled at $1 \mathrm{MHz}$.

During the 6:30-hr duration of the injection experiment, starting at $10 \mathrm{hr}$ on 9 February 2017, 29 active seismic surveys were performed. For obtaining high-precision traveltimes of the first arriving seismic waves, the first arriving wave trains of the 28 monitoring data sets were cross-correlated with the corresponding waveforms of a pilot data set, which was recorded prior to the fluid injection experiment. For this purpose, data were band-pass filtered in the range of $1-8 \mathrm{kHz}$ for the hammers and $1-20 \mathrm{kHz}$ for the piezo sources, with the dominant frequency within the first arriving wave train being $2 \mathrm{kHz}$ for the hammer data and $8 \mathrm{kHz}$ for the piezo sources. Data were then upsampled to a sampling rate of $10 \mathrm{MHz}$, and a tapered window from $0.2 \mathrm{~ms}$ before to $1.8 \mathrm{~ms}$ after the first arrival ( -0.1 to $0.4 \mathrm{~ms}$ for the piezo sources) was extracted for the correlation analysis (Figure S1). The difference in arrival time between the pilot trace and the monitoring data was then determined by finding the time lag that maximizes the correlation of the two waveforms (right panels in Figures S1 and S2). For more than 75\% of all source-receiver pairs, the correlation between the pilot and time-shifted monitoring data remains above 0.99 throughout the experiment and only traces with a correlation above 0.9 are considered for the following analysis. The decorrelation is used as a measure of uncertainty, and the assumed traveltime difference error is calculated as $\varepsilon=(1-$ corr $) \times$ ef $+0.1 \mu$ s with ef $=10 \mu \mathrm{s}$ for the hammer and ef $=2 \mu \mathrm{s}$ for the piezo data. Due to the higher frequency of the piezo-source data and generally stronger hammer signals, correlations generally remain higher for the hammer data.

The traveltime differences throughout the experiment show a clear response to the four injection cycles (Figures $1 \mathrm{~b}$ and S2). Traveltimes associated with ray paths through the pressurized rock volume generally show an increase of traveltime during the high-pressure water injections, while ray paths not traveling through this volume show no change in traveltime. The traveltime variations are rather small: $75 \%$ of all traveltime time series show variations of $<0.1 \%$, and only one source-receiver pair exhibits variations larger than $1 \%$. 

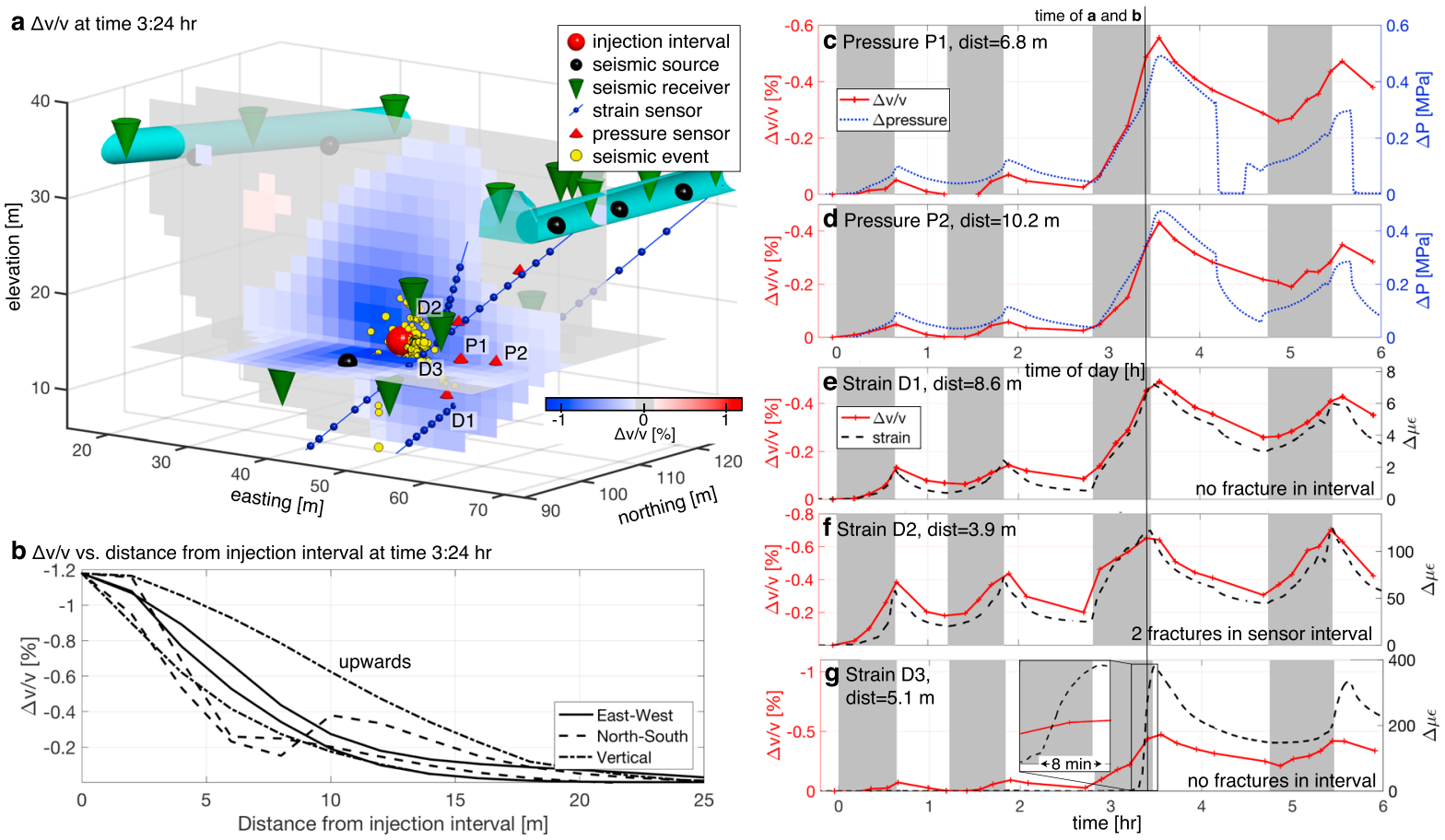

Figure 2. Seismic velocity changes $\Delta v / v$ and comparison with pressure and strain observations. (a) Cuts and (b) profiles of $\Delta v / v$ at time $3: 24$ hr, shown with the induced seismicity cloud and the locations of sensors shown in (c-g). (c-g) Pressure and strain evolution over time along with velocity variations, extracted at the sensor locations (positive strain corresponds to tension). Observe the different $y$ axis scale for the strain measurements. The zoom subfigure in (g) highlights the long duration of the strong deformation slip event.

\section{Time-Lapse Traveltime Inversions}

The traveltime differences along with their estimated uncertainties are used in a deterministic 3-D inversion for the time-dependent seismic velocity changes throughout the experiment. The regularized linear inversion directly uses the traveltime differences to estimate velocity differences from a reference model. The heterogeneous anisotropic 3-D reference model (Figure S3) was estimated using inversion of a comprehensive traveltime data set ( $>10,000$ data points) and is used here to calculate ray paths and data sensitivities. The linearized inversion assumes that the ray paths do not change during the experiment, which is reasonable with maximum traveltime variations of $\leq 1 \%$ and maximum velocity changes of $1.5 \%$ inside the medium.

The time-lapse inversion is performed on a 3-D model covering the experimental volume with a discretization of $2 \mathrm{~m}$ in all directions. The time-lapse inversions fit the data (i.e., changes in traveltime) to the assigned data uncertainties and deliver for the time of each seismic survey a 3-D tomogram of change in velocity compared to the results from the pilot experiment (i.e., the first survey performed before start of the stimulation). The inversion was performed for each of the 29 active seismic monitoring surveys during the experiment, yielding a 4-D seismic velocity model of the rock volume. Examples of time-lapse tomograms are shown in Figures $2 a$ and S4.

\section{Analysis of Seismic Velocity Variations}

The 3-D inversions of the transient traveltime changes show a decrease in seismic velocity around the injection point (Figures $2 \mathrm{a}$ and S4) as a direct response to the high-pressure water injections. Changes in velocity at the injection point already occurred for injection pressures larger than $3 \mathrm{MPa}$ achieved with a flow rate of only $1.5 \mathrm{~L} / \mathrm{min}$ and became strongest during the maximum injection with a pressure of $7.7 \mathrm{MPa}$ and injection rate of $25 \mathrm{~L} / \mathrm{min}$. During the latter phase the velocity changes reached values of $-1.5 \%$ at the injection point and around $-0.6 \%$ at the location of the closest pressure and strain sensors, 6.8 and $3.9 \mathrm{~m}$ from the injection point (Figures $2 \mathrm{c}$ and $2 \mathrm{f}$ ). The velocity change dropped fastest in north and south directions from the injection point-perpendicular to the shear zone strike. Within the shear zone, the velocity perturbation falloff is 

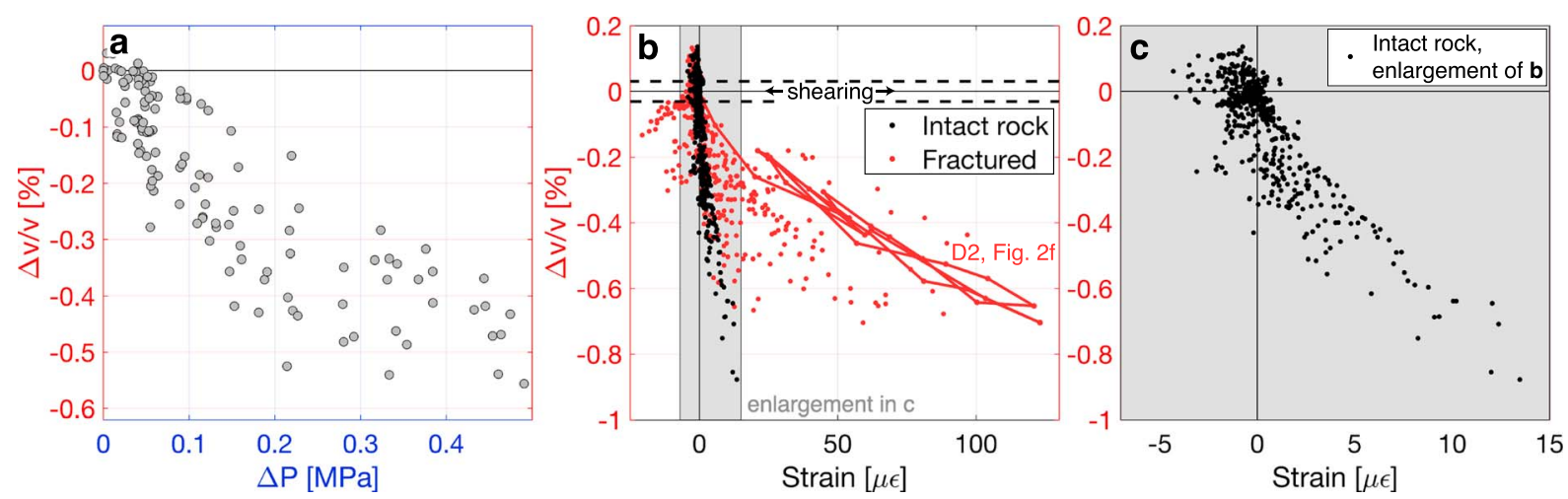

Figure 3. Relationship between change in velocity $\Delta v / v$, pressure $\Delta P$, and strain. (a) $\Delta P-\Delta v / v$ and (b, c) strain-change in velocity $\Delta v / v$ relationship. For pressure (a) as well as for strain measurements in intact rock (c), a linear relationship with change in velocity can be observed. For fractures, this relationship is fracture dependent (e.g., fracture of Figure $2 f$ shown as red line in b), and irreversible deformation (shearing) has no observable effect on seismic velocity. Note that in (b) and (c), data affected by the strong opening and irreversible deformation at time 3:24 hr (see text) are not shown.

nearly the same in the horizontal directions (east and west), while there is a significant difference in the vertical direction, with a more gradual decrease in the upward direction and a decrease over shorter distance downward (Figure 2b). Outside of the region of decreased velocity around the injection point, areas with an increase of velocity can be observed (Figures 2a and S4). After each injection cycle, pressure was released from the rock volume through venting and velocities recovered partly but did not reach the prestimulation value within the short time before the next injection cycle (Figures $2 \mathrm{c}-2 \mathrm{~g}$ ). After the experiment, velocities recovered to the prestimulation values within $12 \mathrm{hr}$. Extracting the inferred velocity change $\Delta v / v$ from the 3-D tomograms allows direct comparison of $\Delta v / v$ with both pressure change $\Delta P$ and strain recordings within the volume.

\subsection{Linking Seismic Velocity and Fluid Pressure Variations}

The time series of velocity change at the pressure monitoring locations show a high correlation with the direct pressure measurements (Figures $2 \mathrm{c}$ and $2 \mathrm{~d}$ ), with a direct response to each injection cycle. Even the short time delay (of 6-8 $\mathrm{min}$ ) of the maximum pressure compared to the stimulation shut-in time can be observed in the seismic response. Plotting $\Delta v / v$ against $\Delta P$ for all sensors and recording times reveals a strong correlation (correlation coefficient of -0.86 ) between change in velocity and pressure (Figure $3 a$ ).

We attribute the high correlation between observed pressure change $\Delta P$ and change in seismic velocity to the dependency of seismic wave speed to the effective stress $\sigma^{\text {ef }}$, an effect that is related to the stress dependency of the elastic constants and is known from laboratory tests (see Text S1 and Eberhart-Phillips et al., 1989). The effective stress is the actual net stress applied to the rock skeleton due to superposition of both mechanical (in situ) stress and the pore pressure: $\sigma_{i}^{e f}=\sigma_{i}-\alpha P$. Here $\sigma_{i}^{e f}$ and $\sigma_{i}$ are effective and mechanical stress tensors, respectively, $\alpha$ is the Biot coefficient, and $P$ is the pore pressure. Most rocks show a nonlinear deformational behavior with the elastic moduli decreasing with decreasing stress due the opening of microcracks and flaws. Therefore, an increase of the pore pressure results in a decrease in the elastic moduli and wave velocity. While this effect is well known (Eberhart-Phillips et al., 1989), experimental evidence directly linking pressure and velocity has to date been restricted to laboratory measurements, where high effective stress variations can be achieved. Here we demonstrate that even small ( $<0.1 \mathrm{MPa}$ ) changes in pore pressure can be measured in field experiments using active seismic tomography with favorable geometry.

\subsection{Comparing Seismic Velocity Variations and Strain}

The comparison of velocity and strain measurements reveals three distinct patterns: (i) Sensors in intact rock show extension, which is proportional to the velocity reduction (Figure 2e) and the proportionality coefficient is roughly the same for all sensors (Figures $3 b$ and $3 c$ ). This extension might be an expression of the elastic deformation of the rock as the increased pore pressure counteracts stresses compressing the rock. (ii) For strain sensors across fractures within the shear zone, the link between velocity change and strain signal is strong (Figure $2 \mathrm{f}$ ) but unique for each fracture (Figure $3 \mathrm{~b}$ ). We attribute this fracture-dependent linear proportionality to a difference in fracture stiffness and orientation with respect to the in situ stress field. With the 
same pressure increase, which is sensed by the seismic tomography, different fractures will show a different aperture change, which is here measured with the strain sensors, yielding different strain magnitudes. The strain curves in Figures $2 \mathrm{e}$ and $2 \mathrm{f}$ return to zero within $12 \mathrm{hr}$ after the experiment and thus represent reversible strain, while the sensor shown in Figure $2 \mathrm{~g}$ experiences irreversible strain of $\sim 120 \mu \varepsilon$. (iii) Such irreversible deformation (e.g., shear dislocation) recorded by the strain sensors is not evident in the velocity tomograms. For example, Figure $2 \mathrm{~g}$ shows a strong extensional signal, which is expression of shearing and opening of a previously undetected fracture. The major deformation event happens over the course of about $8 \mathrm{~min}$ and has no expression in the seismic tomograms. We suspect a microfracture that was reactivated in a combined opening and shear mode without emitting detectable seismic signals. Most microfractures in our rock volume are oriented subparallel to shear zone S1 or S3. The irreversible rock deformation related to shearing does not have a significant volumetric component, so that the seismic velocity changes are too small to be detected. Due to the opening at the sensor shown in Figure 2g, the surrounding rock is being compressed. For sensors capturing this compression, which is due to high stress transformation, the measured strain does not correlate to the change in velocity and they are thus excluded from Figures $3 b$ and 3c. Using this departure from the correlation between strain and change in velocity makes it possible to distinguish primary poroelastic effects from secondary mechanical deformation, for example, compression induced by the opening of an individual fracture. These results indicate that seismic velocity changes measure changes in effective stress-producing volumetric strain-while shear dislocation is not discernible through seismic velocity.

\subsection{The 3-D Pressure Propagation}

The link between change in seismic velocities and pore pressure allows interpretation of the seismic tomograms in terms of fluid pressure migration. Figure $2 b$ shows the fastest decay of pressure perturbation in north-south direction, perpendicular to the stimulated shear and fracture zone. Thus, the fluid propagates mostly within this shear and fracture zone, as may be expected. Within the shear zone, the pressure propagation is symmetric in east and west directions. The faster decay of the pressure perturbation downward compared to upward (Figure 2b) might be explained with the natural gradient of the pore pressure and the stress field gradient in the system: during stimulation the upward pore pressure gradient is slightly larger than the downward pressure gradient. At the same time, the vertical stress gradient may lead to an increasing fracture permeability in upward direction. Together, these two effects accrue to promote enhanced upward pressure propagation.

\subsection{Poroelastic Compression}

Outside the regions of decrease in velocity, zones of an increase in velocity can be observed (Figures $2 \mathrm{a}$ and S4). We interpret these zones of increased velocity as areas of compression that compensate the extension of the rock within the pressurized volume. In these zones, confining stress is locally increased, leading to an increase in velocity. The borehole traces of strain and change in pressure in Figure S6 support this interpretation, as they show both the decrease in velocity along with extension (positive strain) in the deeper parts of the boreholes near the injection point and the slight increase in velocity due to the compaction (negative strain) of the rock. Our observations confirm predictions by Segall and Lu (2015), who describe compressive regions around the volume perturbed by fluid pressure that may inhibit fault slip during injection.

\subsection{Comparison With Laboratory Measurements}

To verify the link between seismic velocity change and the pressurization of the rock, we performed laboratory measurements on cores from the boreholes within the experimental volume (Nejati, 2018). A transversely isotropic material model was used to characterize the deformation response and the stress dependency of the elastic moduli. We used uniaxial compression tests to obtain the static elastic moduli, while ultrasonic measurements were used to obtain the dynamic moduli (see Text S1 for details). Assuming that the in situ stress remains constant during the injection, the change of the effective stress is negatively correlated to the change of fluid pressure, with Biot coefficient $\alpha$ being the proportionality constant: $\Delta \sigma_{i}^{\text {ef }}=-\alpha \Delta P$. This indicates that the rate of effective stress drop is proportional to the rate of pore pressure increase. We now use the laboratory data given in Table S1 for the stress dependency of elastic moduli and a Biot coefficient of $\alpha=0.7$ (reported for Barre granite; Bernabe, 1986) to predict the fluid pressure change based on the velocity measurements. 


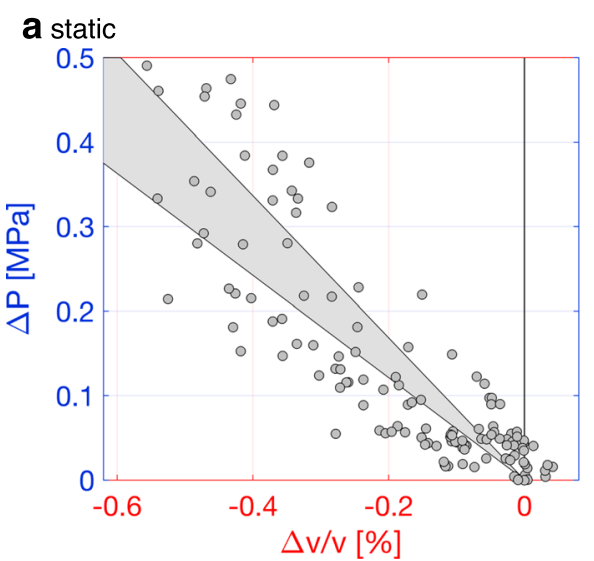

b dynamic

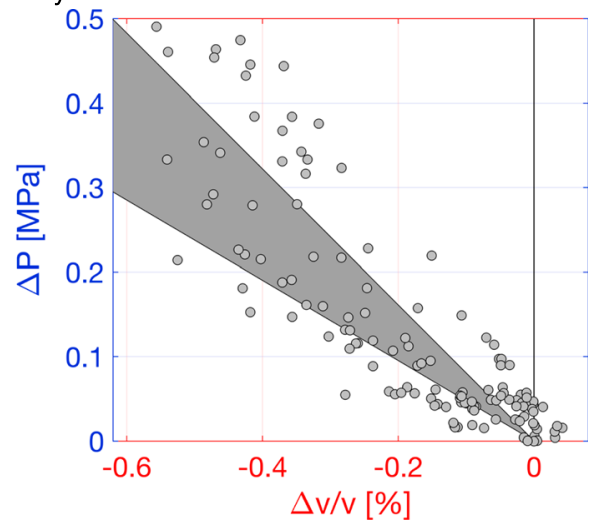

Figure 4. Prediction of the pore pressure change using laboratory data on the dependency of (a) static and (b) dynamic elastic moduli on the effective stress. Data points are the field measurements, while the shaded areas are bounded with two lines which show the dependency of the pressure change on the velocity change within and normal to the foliation plane.

Figure 4 compares the prediction of the pressure change based on the laboratory data (shaded areas) with the actual data obtained from the field measurements. These plots show that the change in fluid pressure can be indeed predicted very well by the seismic measurement when laboratory data on the pressure dependency of elastic moduli or wave velocity are available and the Biot's coefficient is known. It is seen that both static and dynamic measurements provide good predictions of the change in fluid pressure based on the velocity values.

\subsection{Comparison to Induced Seismicity}

Numerous ( $>2000$ ) seismic events with magnitudes smaller than -2 were detected and located during the fluid injection experiment, with seismic events occurring at injection pressures larger than $7 \mathrm{MPa}$, the predicted slip activation pressure for the $\mathrm{S} 3$ shear zone. Similar pressure thresholds defining the onset of seismicity were also observed during stimulations at greater depths (e.g., $5 \mathrm{MPa}$ at Soultz-sous-forêt, Evans et al., 2005 and $10 \mathrm{MPa}$ in Rosemanowes, Baria \& Green, 1989) and were found to be indicative of how critically stressed the rock mass is. At Grimsel, seismic events cluster within a volume of 5-m radius around the injection point (Figures 2a and S5), although pressure and strain propagate much farther. This illustrates that fluid pressure and possibly irreversible fracture deformation may migrate farther than indicated by the current seismic cloud.

\subsection{Implications for Injections at Great Depths}

The experiment presented here with a total injection volume of $1.25 \mathrm{~m}^{3}$ is small compared to reservoir stimulations for oil and gas production, associated wastewater injections (Ellsworth, 2013), or development of enhanced geothermal reservoirs (Evans et al., 2005; Häring et al., 2008). However, since seismic velocities can readily be measured and monitored on many scales, there appears strong potential for enabling remote pressure monitoring for large-scale applications. For target volumes at depths prohibiting direct active measurements, velocities can be monitored using local earthquake tomography (Calò et al., 2011), interferometry of seismic noise (e.g., Brenguier et al., 2014), or interferometry using a repeated natural source, such as volcanic tremors (Donaldson et al., 2017). Seismic velocity monitoring could be a way of monitoring pressure evolution, which is important to assess the risk of fault reactivation. For seismic events near fluid injection wells, knowing the pressurized volume could also help determine, if an event was injection induced or natural, a question of high societal importance that is inherently difficult to answer (Ellsworth, 2013).

\section{Conclusions}

Active seismic transmission data recorded during a $1.25-\mathrm{m}^{3}$ water injection experiment show a direct response to the high-pressure fluid injection cycles. Inversion of these data yields a transient 3-D seismic velocity model of the injection volume. Comparison with fluid pressure measured within the rock volume reveals 
Acknowledgments

This study is part of the In situ Stimulation and Circulation (ISC) project established by the Swiss Competence Center for Energy Research-Supply of Electricity (SCCER-SoE) with the support of Innosuisse. Funding for the ISC project was provided by the ETH Foundation with grants from Shell and EWZ and by the Swiss Federal Office of Energy through a P\&D grant. Hannes Krietsch is supported by SNF grant 200021_169178; Linus Villiger is supported by grant ETH-35 16-1. The Grimsel Test Site is operated by Nagra, the National Cooperative for the Disposal of Radioactive Waste. We are indebted to Nagra for hosting the ISC project in their facility and to the Nagra technical staff for onsite support. The authors thank Carolina Giorgetti and Brett Carpenter for their constructive reviews. All data used for the analysis are available at doi:10.3929/ethz-b000253941. Text S1, Table S1, and Figures S1-S6 are available in the supporting information. a strong correlation, which enables prediction of subsurface fluid pressure based on the seismic velocity variations. The link between seismic velocity variations and rock deformation is more complex, with a clear link existing for reversible deformation driven by the fluid pressure-related stress change. However, we find that seismic velocities show no trace of irreversible deformation such as shear displacement. We conclude that seismic velocity changes measure volumetric strain resulting from effective stress changes, while shear dislocation does not affect seismic velocity.

During deep hydraulic stimulations, seismic velocity variations can be recorded (Calò et al., 2011; Hillers et al., 2015; Obermann et al., 2015), while pressure and rock deformation cannot be directly measured. Our results show that the observation of velocity changes could then be used as proxy for the pressurized volume. We propose to combine seismic velocity with induced seismicity monitoring so that the rock volume with induced seismicity may serve as a lower bound of the stimulated volume, while the pressurized volume estimated from velocity changes can act as the upper bound.

\section{References}

Amann, F., Gischig, V., Evans, K., Doetsch, J., Jalali, R., Valley, B., et al. (2018). The seismo-hydromechanical behavior during deep geothermal reservoir stimulations: Open questions tackled in a decameter-scale in situ stimulation experiment. Solid Earth, 9(1), 115-137. https://doi. org/10.5194/se-9-115-2018

Baria, R., \& Green, A. S. P. (1989). Microseismics: A key to understanding reservoir growth. In Proc. Hot Dry Rock Conference, Ed. Roy Baria, Camborne School of Mines Redruth, Robertson Scientific Publications, London (pp. 363-377).

Bernabe, Y. (1986). The effective pressure law for permeability in Chelmsford granite and Barre granite. International Journal of Rock Mechanics and Mining Science and Geomechanics Abstracts, 23(3), 267-275. https://doi.org/10.1016/0148-9062(86)90972-1

Brenguier, F., Campillo, M., Takeda, T., Aoki, Y., Shapiro, N. M., Briand, X., et al. (2014). Mapping pressurized volcanic fluids from induced crustal seismic velocity drops. Science, 345(6192), 80-82. https://doi.org/10.1126/science.1254073

Calò, M., Dorbath, C., Cornet, F. H., \& Cuenot, N. (2011). Large-scale aseismic motion identified through 4-D P-wave tomography. Geophysical Journal International, 186(3), 1295-1314. https://doi.org/10.1111/j.1365-246X.2011.05108.x

Chiarabba, C., Gori, P. D., \& Boschi, E. (2009). Pore-pressure migration along a normal-fault system resolved by time-repeated seismic tomography. Geology, 37(1), 67-70. https://doi.org/10.1130/G25220A.1

Cipolla, C., \& Wallace, J. (2014). Stimulated reservoir volume: A misapplied concept? Presented at the SPE hydraulic fracturing technology conference. Society of Petroleum Engineers.. https://doi.org/10.2118/168596-MS

Cornet, F. H., Helm, J., Poitrenaud, H., \& Etchecopar, A. (1997). Seismic and aseismic slips induced by large-scale fluid injections. Pure and Applied Geophysics, 150(3-4), 563-583. https://doi.org/10.1007/s000240050093

Donaldson, C., Caudron, C., Green, R. G., Thelen, W. A., \& White, R. S. (2017). Relative seismic velocity variations correlate with deformation at Kïlauea volcano. Science Advances, 3(6), e1700219. https://doi.org/10.1126/sciadv.1700219

Duboeuf, L., De Barros, L., Cappa, F., Guglielmi, Y., Deschamps, A., \& Seguy, S. (2017). Aseismic motions drive a sparse seismicity during fluid injections into a fractured zone in a carbonate reservoir. Journal of Geophysical Research: Solid Earth, 122, 8285-8304. https://doi.org/ 10.1002/2017JB014535

Eberhart-Phillips, D., Han, D., \& Zoback, M. (1989). Empirical relationships among seismic velocity, effective pressure, porosity, and clay content in sandstone. Geophysics, 54(1), 82-89. https://doi.org/10.1190/1.1442580

Ellsworth, W. L. (2013). Injection-induced earthquakes. Science, 341(6142). https://doi.org/10.1126/science.1225942

Evans, K. F. (1998). Does significant aseismic slip occur on fractures in HDR systems under stimulation conditions. In Pre-conference proc. of 4th Int. Hot Dry Rock Forum, SOCOMINE, Kutzenhausen, France (Vol. 28, p. 30). http://www.geothermal.ethz.ch/content/Geothermal\% 20publications/Evans_1998_4thHDRforum.pdf

Evans, K. F., Moriya, H., Niitsuma, H., Jones, R. H., Phillips, W. S., Genter, A., et al. (2005). Microseismicity and permeability enhancement of hydrogeologic structures during massive fluid injections into granite at $3 \mathrm{~km}$ depth at the Soultz HDR site. Geophysical Journal International, 160(1), 389-412. https://doi.org/10.1111/j.1365-246X.2004.02474.x

Gischig, V. S., Doetsch, J., Maurer, H., Krietsch, H., Amann, F., Evans, K. F., et al. (2018). On the link between stress field and small-scale hydraulic fracture growth in anisotropic rock derived from microseismicity. Solid Earth, 9(1), 39-61. https://doi.org/10.5194/se-9-39-2018

Guglielmi, Y., Cappa, F., Avouac, J.-P., Henry, P., \& Elsworth, D. (2015). Seismicity triggered by fluid injection-induced aseismic slip. Science, 348(6240), 1224-1226. https://doi.org/10.1126/science.aab0476

Häring, M. O., Schanz, U., Ladner, F., \& Dyer, B. C. (2008). Characterisation of the Basel 1 enhanced geothermal system. Geothermics, 37(5), 469-495. https://doi.org/10.1016/j.geothermics.2008.06.002

Hillers, G., Husen, S., Obermann, A., Planès, T., Larose, E., \& Campillo, M. (2015). Noise-based monitoring and imaging of aseismic transient deformation induced by the 2006 Basel reservoir stimulation. Geophysics, 80(4), KS51-KS68. https://doi.org/10.1190/geo2014-0455.1

Husen, S., Bachmann, C., \& Giardini, D. (2007). Locally triggered seismicity in the central Swiss Alps following the large rainfall event of August 2005. Geophysical Journal International, 171(3), 1126-1134. https://doi.org/10.1111/j.1365-246X.2007.03561.x

Keusen, H., Ganguin, J., Schuler, P., \& Buletti, M. (1989). Felslabor Grimsel: Geologie. NAGRA Technical Report 87-14.

Kodaira, S., lidaka, T., Kato, A., Park, J.-O., Iwasaki, T., \& Kaneda, Y. (2004). High pore fluid pressure may cause silent slip in the Nankai Trough. Science, 304(5675), 1295-1298. https://doi.org/10.1126/science.1096535

Krietsch, H., Doetsch, J., Dutler, N., Jalali, M., Gischig, V., Loew, S., \& Amann, F. (2018). Comprehensive geological dataset for a fractured crystalline rock volume at the Grimsel Test Site. doi:https://doi.org/10.3929/ethz-b-000243199

Krietsch, H., Gischig, V., Jalali, M., Doetsch, J., Valley, B., \& Amann, F. (2018). A comparison of FBG-and Brillouin-strain sensing in the framework of a decameter-scale hydraulic stimulation experiment. In American Rock Mechanics Association (ARMA).

Krietsch, H., Gischig, V., Evans, K. F., Doetsch, J., Dutler, N., Valley, B., \& Amann, F. (2018). Stress measurements for an in-situ stimulation experiment in crystalline rock: Integration of induced seismicity, stress relief and hydraulic methods. Rock Mechanics and Rock Engineering https://doi.org/10.1007/s00603-018-1597-8

Mayerhofer, M. J., Lolon, E., Warpinski, N. R., Cipolla, C. L., Walser, D. W., \& Rightmire, C. M. (2010). What is stimulated reservoir volume? SPE Production \& Operations, 25(01), 89-98. https://doi.org/10.2118/119890-PA 
Miller, S. A., Collettini, C., Chiaraluce, L., Cocco, M., Barchi, M., \& Kaus, B. J. P. (2004). Aftershocks driven by a high-pressure $\mathrm{CO}_{2}$ source at depth. Nature, 427(6976), 724-727. https://doi.org/10.1038/nature02251

Nejati, M. (2018). On the anisotropy of mechanical properties in Grimsel granodiorite. ETH Zurich. https://doi.org/10.3929/ethz-b-000289969

Obermann, A., Kraft, T., Larose, E., \& Wiemer, S. (2015). Potential of ambient seismic noise techniques to monitor the St. Gallen geothermal site (Switzerland). Journal of Geophysical Research: Solid Earth, 120, 4301-4316. https://doi.org/10.1002/2014JB011817

Pezzo, G., De Gori, P., Lucente, F. P., \& Chiarabba, C. (2018). Pore pressure pulse drove the 2012 Emilia (Italy) series of earthquakes. Geophysical Research Letters, 45, 682-690. https://doi.org/10.1002/2017GL076110

Rivet, D., De Barros, L., Guglielmi, Y., Cappa, F., Castilla, R., \& Henry, P. (2016). Seismic velocity changes associated with aseismic deformations of a fault stimulated by fluid injection. Geophysical Research Letters, 43, 9563-9572. https://doi.org/10.1002/2016GL070410

Sayers, C., Johnson, G., \& Denyer, G. (2002). Predrill pore-pressure prediction using seismic data. Geophysics, 67(4), 1286-1292. https://doi. org/10.1190/1.1500391

Segall, P., \& Lu, S. (2015). Injection-induced seismicity: Poroelastic and earthquake nucleation effects. Journal of Geophysical Research: Solid Earth, 120, 5082-5103. https://doi.org/10.1002/2015JB012060

Shapiro, S. A., Huenges, E., \& Borm, G. (1997). Estimating the crust permeability from fluid-injection-induced seismic emission at the KTB site. Geophysical Journal International, 131(2), F15-F18. https://doi.org/10.1111/j.1365-246X.1997.tb01215.X

Shapiro, S. A., Rentsch, S., \& Rothert, E. (2005). Characterization of hydraulic properties of rocks using probability of fluid-induced microearthquakes. Geophysics, 70(2), F27-F33. https://doi.org/10.1190/1.1897030

Wenning, Q. C., Madonna, C., de Haller, A., \& Burg, J.-P. (2018). Permeability and seismic velocity anisotropy across a ductile-brittle fault zone in crystalline rock. Solid Earth, 9(3), 683-698. https://doi.org/10.5194/se-9-683-2018 